\title{
STRATEGI PENGEMBANGAN BISNIS RHYTHM OF EMPOWERMENT DENGAN PENDEKATAN MODEL BISNIS KANVAS
}

\section{THE RHYTHM OF EMPOWERMENT BUSINESS DEVELOPMENT STRATEGY THROUGH BUSINESS MODEL CANVAS APPROACH}

\author{
Budi Bagus Prasetyo*), Lukman M. Baga ${ }^{* *}$, dan Lilik Noor Yuliati* \\ *) PT. Cahaya Pagi \\ Komplek Soho Green Valley Blok B.2 No. 03 Bogor Nirwana Resident, Bogor 16135 \\ ${ }^{* *}$ Departemen Agribisnis, Fakultas Ekonomi dan Manajemen, Institut Pertanian Bogor \\ Jl. Agatis Kampus IPB Darmaga, Bogor 16880 \\ ${ }^{* * *}$ Departemen Ilmu Keluarga dan Konsumen Fakultas Ekologi Manusia Institut Pertanian Bogor \\ Jl. Lingkar Akademik, Kampus IPB Dramaga, Bogor 16680
}

\begin{abstract}
Rhythm of Empowerment (ROE) is a business division of PT. Cahaya Pagi, focusing on soft skills training. ROE is currently facing various challenges in competition, such as ways to achieve targeted working performance, acceleration in vision/mission accomplishment, and management of ROE human resources to face competition. The objective of this research was to design future ROE business model by using descriptive analysis method on a case study of ROE. The data were colected using Focus Group Discussions, interviews, observations, and literature study. Business model canvas (BMC) and SWOT analysis were used as analysis tools. The research results on customer segment showed an indication of segment expansion. Thus, the results also showed that the proportion value was added with product innovation, channels were strengthened in all lines, customer relationship was optimized by using IT, revenue stream was developed by creating other income, and organization was restructured to improve key human resources. Meanwhile, in the activities, some additional activities were added, key partnership was added with marketing partners and finance, tax, and production consultants. The cost structure was allocated to recruit new partners. In conclusion, ROE needs to improve 9 $B M C$ elements of its current business model to the new BMC of ROE.
\end{abstract}

Keywords: SWOT, BMC, soft skills training, value proposition, channels

\begin{abstract}
Abstrak: Rhythm of Empowerment (ROE) adalah sebuah divisi bisnis dari PT. Cahaya Pagi yang bergerak di bidang pelatihan soft skills. Saat ini ROE memiliki berbagai kendala dan tantangan yang dihadapi antara lain bagaimana mencapai target kinerja dan melakukan akselerasi untuk mencapai visi dan misi perusahaan serta mengelola sumber daya ROE dalam menghadapi persaingan. Penelitian ini bertujuan merancang model bisnis di masa depan untuk ROE. Metode yang digunakan adalah analisis deskriptif studi kasus pada ROE, tehnik pengambilan data melalui Focus Group Discussion, wawancara, observasi dan studi literatur, sedangkan alat analisa menggunakan model bisnis kanvas (BMC) dan analisis SWOT. Hasil penelitian menunjukkan pada segmen pelanggan, terdapat perluasan segmen. Nilai proposisi ditambah dengan inovasi produk, saluran diperkuat disemua lini, hubungan pelanggan dioptimalkan melalui IT, arus pendapatan ditingkatkan dengan penciptaan pendapatan lain, restrukturisasi organisasi untuk perbaikan sumber daya kunci, sedangkan aktivitas kunci terdapat penambahan beberapa aktivitas, kemitraan kunci ditambah dengan mitra pemasaran dan konsultan keuangan, pajak serta produksi. Struktur biaya ditambahkan untuk perekrutan mitra-mitra baru. Maka dapat disimpulkan bahwa ROE perlu melakukan perbaikan terhadap 9 elemen BMC dari model bisnis saat ini yang dituangkan dalam BMC baru ROE
\end{abstract}

Kata kunci: SWOT, BMC, pelatihan soft skills, proporsi nilai, saluran

\footnotetext{
${ }^{1}$ Alamat Korespondensi:

Email: bagus.roe@gmail.com
} 


\section{PENDAHULUAN}

Sumber daya manusia dianggap sebagai salah satu faktor produksi penting selain sumber daya alam, modal untuk menghasilkan output. Semakin tinggi kualitas sumber daya manusia, maka semakin meningkat pula efisiensi dan produktivitas suatu perusahaan atau organisasi. Penekanan pada investasi manusia diyakini merupakan basis dalam meningkatkan produktivitas faktor produksi secara total (Solihin, 1995).

Investasi ini tidak hanya meliputi investasi dalam bentuk hard skills tetapi juga soft skills yang diperlukan agar setiap individu mampu membangun perilaku positif yang mampu mendukung kinerja individu dan kinerja organisasi atau perusahaan untuk perkembangan yang lebih baik (Ahdiyana, 2010).

Pelatihan soft skills di Indonesia memiliki potensi bisnis yang besar dengan ditandai hadirnya berbagai nama besar seperti Mario Teguh, Merry Riana dan lainnya. Salah satunya adalah ESQ 165 yang diciptakan oleh Ary Ginanjar, menurut laman dari sebuah website yaitu gerakjalanesq.wordpers.com tahun 2017 dalam 15 tahun ESQ 165 telah memiliki alumni 1.500 .000 orang tersebar dari Indonesia hingga ke mancanegara. Jika dengan rata-rata harga pelatihan per orang termurah menurut www.esqways165.com tahun 2017 senilai Rp2.500.000,- dan dikalikan antara jumlah alumni dan harga per orang untuk mengikuti pelatihan ESQ 165 maka ESQ 165 memiliki pendapatan sebesar Rp3.750.000.000.000,- untuk 15 tahun terkahir itupun belum dari produk-produk lainnya yang memiliki harga pelatihan bervariasi.

Salah satu bisnis yang menjadi pemain dalam bidang ini adalah PT. Cahaya Pagi yang memiliki produk jasa pelatihan dengan banyak varian metode dan materi pelatihan soft skills. Pada bulan Maret tahun 2015, PT. Cahaya Pagi meluncurkan divisi bisnis baru, yaitu Rhythm of Empowerment (ROE) yang menggunakan metode unik dan kreatif melalui musik sebagai media untuk penyampaian materi-materi pelatihan. ROE sendiri saat ini telah tampil dihadapan ribuan peserta dari berbagai perusahaan maupun institusi pemerintahan.

ROE mengalami peningkatan omzet dari tahun ke tahun tetapi kinerja ROE masih belum dapat mencapai target yang dicanangkan oleh perusahaan untuk tahun 20142016. Namun, ROE dari tahun 2014-2016 mengalami pertumbuhan yang signifikan, tentunya hal ini juga memiliki implikasi tersendiri bagi ROE yaitu adanya kendala yang dihadapi dalam pengelolaan organisasi dan sumber daya ROE dirasa belum cukup untuk merespon peningkatan omzet dari ROE yang signifkan. omzet ROE tergolong masih relatif kecil jika dibanding besarnya besarnya potensi pasar pelatihan soft skills di Indonesia. Berikut pencapaian dan pertumbuhan omzet dari ROE bisa dilihat pada Tabel 1 .

Didalam dunia persaingan bisnis yang semakin ketat membuat perusahaan-perusahaan harus memiliki visi, misi, dan ide-ide baru agar dapat beradaptasi terhadap perubahan lingkungan (Eppler et al. 2011). ROE sendiri telah memiliki visi dan misi serta milestone statement hingga tahun 2025. Selain pencapaian target kinerja, penguatan posisi branding ROE untuk menjadi perusahaan pelatihan dan konsultasi terpandang di Asia Tenggara menjadi visi jangka panjang ROE.

Dari berbagai kendala dan tantangan diatas untuk itu ROE membutuhkan model bisnis yang tepat guna pencapaian target kinerja yang telah dicanangkan dan mampu melakukan akselerasi untuk mencapai visi dan misi perusahaan dan mengelola organisasi dan sumber daya. ROE juga harus siap menghadapi persaingan dengan nama-nama besar yang sudah ada di bidang pelatihan soft skills dalam menangkap peluang yang ada dengan besarnya potensi di bisnis pelatihan soft skills di Indonesia.

Sejak tahun 1995 sudah banyak jurnal dan artikel ilmiah dengan fokus utama pembahasan berbagai ide dan gagasan tentang model bisnis telah diterbitkan (Zott et al. 2010). Bisnis adalah proses menciptakan nilai dan memenangkan kembali nilai itu dan model hanyalah sebuah representasi dari realitas (Shafer et al. 2005). Model bisnis yang digunakan oleh perusahaan harus dapat menghasilkan uang atau nilai di lingkungan bisnis dimana perusahaan tersebut beroperasi (Wheelan, 2008). Artinya, ROE harus memiliki model bisnis yang mampu menjawab perkembangan dari perusahaan dalam mengelola proses operasional dan manajemen dari ROE sendiri terutama dalam menciptakan dan mempertahankan pelanggan ditengah persaingan bisnis dan bagaimana menggarap potensi besar yang ada sehingga mampu menghasilkan uang atau nilai lebih besar dan cepat dikarenakan, syarat yang harus dipenuhi oleh suatu perusahaan agar sukses dalam persaingan adalah berusaha mencapai tujuan untuk menciptakan dan mempertahankan pelanggan (Amreny, 2012). 
Tabel 1. Omzet ROE Tahun 2014-2016

\begin{tabular}{llll}
\hline Tahun & $\begin{array}{l}\text { Target Omzet } \\
\text { (Rp.) *dalam } \\
\text { Juta }\end{array}$ & $\begin{array}{l}\text { Realisasi } \\
\text { Omzet (Rp.) } \\
\text { *dalam Juta }\end{array}$ & Pencapaian \\
\hline 2014 & 3.500 & 2.061 & $58,88 \%$ \\
2015 & 5.750 & 4.346 & $75,58 \%$ \\
2016 & 6.800 & 5.247 & $77,16 \%$ \\
\hline
\end{tabular}

Sumber: PT. Cahaya Pagi (2016)

Model bisnis adalah sebuah atraksi yang menggambarkan suatu bisnis tidak pada tingkat operasional, tetapi pada tingkat konseptual, mengumpamakan bahwa model bisnis suatu perusahaan memenuhi dua tujuan yang saling terkait (Cavalcante et al. 2011). Selanjutnya, Leschke (2013) menyatakan bahwa pemodelan bisnis ini berlaku luas, relevan dengan pengusaha, investor, penasihat bisnis dan organisasi nirlaba, sebagaimana juga perusahaan yang akan membuat lini bisnis baru. Salah satu model bisnis yang berhasil mengubah konsep bisnis yang rumit menjadi sederhana dan mudah dipahami adalah Model Bisnis Kanvas (BMC) Model Bisnis Kanvas adalah bahasa umum untuk menggambarkan, memvisualisasikan, menilai dan mengubah model bisnis (Maghfirah, 2012). Model bisnis kanvas adalah alat yang memberikan pandangan yang jelas tentang apa yang perlu dicapai perusahaan dan berfokus pada elemen strategis yang paling penting dan akan memiliki dampak terbesar pada bisnis (Amanullah et al. 2015). Model bisnis ini ditampilkan dalam bentuk kanvas yang terbagi menjadi sembilan elemen utama dan banyak diteliti sekaligus diaplikasikan langsung di berbagai bidang bisnis seperti pada bisnis kuliner teh siap saji (Thamrin, 2016) dan juga rental mobil (Agustiadi et al. 2016) dan untuk penelitian lain di luar negeri juga dilakukan pada Nokia (Aspara et al. 2011) dan juga pada Google (Hone et al. 2011) yang menggunakan BMC.

Jurnal penelitian ini diharapkan dapat membantu mengembangkan perusahaan selain itu juga dapat 1) mengidentifikasi model bisnis di ROE saat ini dengan menggunakan pendekatan model bisnis kanvas; 2) menganalisis faktor internal dan eksternal yang memengaruhi model bisnis dari ROE; 3) merumuskan strategi dan program perbaikan apa saja yang dapat dilakukan dari hasil penyempurnaan model bisnis kanvas ROE untuk pengembangan perusahaan kedepaannya.

\section{METODE}

Ruang lingkup penelitian ini berfokus hanya pada ROE sebagai sebuah brand yang merupakan divisi bisnis dari PT. Cahaya Pagi yang berkantor dikota Bogor. Penelitian dilakukan pada bulan Mei hingga Agustus 2017. Pemilihan lokasi ini dilakukan secara sengaja (purposive).

Ruang lingkup hanya akan fokus pada konsep bisnis model kanvas melalui sembilan elemen kunci yang akan dilanjutkan dengan melakukan analisis SWOT yang diperlukan untuk melihat kekuatan dan kelemahan serta peluang dan ancaman yang ada sehingga mampu menghasilkan rekomendasi berupa strategi penyempurnaan bisnis model yang ada pada saat ini, yang tentunya dapat dirumuskan menjadi implikasi manajerial untuk pengembangan bisnis dari ROE kedepannya.

Data yang digunakan dalam penelitian ini adalah data primer dan sekunder. Data primer berkaitan dengan tujuan spesifik penelitian yakni menjawab rumusan masalah dan menghasilkan strategi pengembangan bisnis (Boedianto, 2015), didapat dari FGD dan wawancara dengan pihak eksternal yang fokus untuk mendapatkan data berupa identifikasi model bisnis di ROE saat ini dan menganalisis faktor internal dan eksternal yang memengaruhi model bisnis dari ROE. Sedangkan untuk pihak internal selain pengambilan data untuk kedua hal tersebut juga ditambahkan untuk penyempurnaan model bisnis kanvas ROE. Berikut daftar responden dapat dilihat pada Tabel 2.

Penelitian ini menggunakan pendekatan deskriptif yang pada dasarnya menggambarkan isi dari suatu objek penelitian (Azis et al. 2013) dengan jenis penelitian studi kasus, sedangkan perumusan strategi menggunakan pendekatan BMC dan analisis SWOT, tehnik pengumpulan data dan infomasi dilakukan melalui: 1) wawancara langsung dan sistematis dengan pihak internal dan eksternal dari ROE; 2) observasi dengan cara pengamatan langsung di lokasi penelitian dan aktivitas bisnis dari objek penelitian; 3) kuisioner dengan cara memberikan sejumlah pertanyaan tertulis kepada responden; 4) studi pustaka yaitu dengan mengkaji data perusahaan dan studi literatur; 5) FGD dengan tim manajemen dipimpin direktur. 
Tabel 2. Daftar responden

\begin{tabular}{lcc}
\hline Daftar responden & Jumlah & Keterangan \\
\hline ROE Arranger & 1 & Responden \\
Operation Mgr & 1 & internal 9 \\
Komisaris & 1 & \\
Sales Coordinator & 1 & \\
Staff & 3 & Responden \\
Mitra swasta & 2 & \\
Mitra pemerintah & 2 & \\
Mitra Universitas & 1 & \\
\hline Total & 12 & \\
\hline
\end{tabular}

Pada kerangka konseptual (Gambar 1) diuraikan bahwa penelitian ini terdiri dari beberapa langkah yaitu pertama dilakukan denganmenganalisa kondisi bisnis ROEuntuk saat ini berdasar BMC. Setelah itu menurut Bonazzi (2014) dilakukan analisa SWOT terhadap masingmasing elemen untuk menciptakan upaya model bisnis yang diperbaki. Metode analisis SWOT merupakan alat yang tepat untuk menemukan masalah dari 4 sisi yang berbeda, yaitu bagaimana kekuatan (strengths) mampu mengambil keuntungan dari peluang (opportunities) yang ada, kemudian bagaimana strategi mengatasi kelemahan (weaknesses) yang dapat merugikan, selanjutnya bagaimana kekuatan (strengths) mampu mereduksi ancaman (threats) yang ada, dan bagaimana cara mengatasi kelemahan (weaknesses) yang dapat menjadi ancaman (threats). Dengan dilakukan analisis SWOT untuk masing-masing elemen maka dapat dirumuskan strategi perbaikan, yang dengan demikian diharapkan tidak hanya melakukan perbaikan. Namun, juga memperbesar peluang terbentuknya inovasi dalam pengembangan model bisnis, termasuk adanya pengembangan di luar kompetensi inti perusahaan (Dewa et al. 2016) sehingga menjadi dasar rujukan perumusan model bisnis baru ROE yang otomatis memiliki implikasi manajerial.

\section{HASIL}

\section{Identifikasi Model Bisnis ROE Saat Ini}

Sebagai langkah awal dalam neyusun strategi pengembangan bisnis ROE yaitu dilakukan dengan memetakan struktur bisnis perusahaan saat ini. Hasil wawancara dan focus group discussion (FGD) dengan beberapa pihak internal perusahaan dan eksternal pelanggan serta mitra utama maka diperoleh beberapa gambaran model pengelolaan bisnis perusahaan yang sudah di terapkan melalui pengelompokan hasil tersebut kedalam sembilan elemen model bisnis kanvas. Berikut pemetaan untuk masing-masing elemen dari model bisnis ROE saat ini, yaitu sebagai berikut:

Customer Segment, ROE telah memiliki segmen pelanggan yang disesuaikan dengan konsep dan isi materi, secara garis besar terdiri atas, yaitu 1) segmen ROE Star untuk kalangan profesional dan karyawan ; 2) ROE for Student untuk pelajar tingkat SMU hingga Mahasiswa; 3) ROE for kids diperuntukkan untuk siswa SD hingga SMP ; 4) ROE Sahabat diperuntukkan untuk panti-panti sosial maupun pesantren-pesantren dengan tujuan sebagai kegiatan CSR bagi ROE.

Value Propositions, menggambarkan nilai atau manfaat yang ditawarkan perusahaan kepada pelanggan (Osterwalder dan Pigneur, 2010), Value Proposition di ROE adalah memiliki sifat kebaruan dengan menonjolkan keunikan dan pertama di Indonesia yaitu konser musik motivasional yang menggunakan filosofi, permainan dan juga tehnologi dalam musik untuk memotivasi peserta. Selain itu materi maupun kemasan dapat disesuikan sesuai keinginan dan kebutuhan dari pelanggan.

Channels atau saluran, ROE memiliki beberapa saluran dalam berkomunikasi dengan pelanggan untuk menentukan dan menciptakan proporsi nilai. Adapun langkah yang diambil oleh perusahaan adalah membangun saluran langsung dan tidak langsung. Untuk saluran langsung, yaitu melalui tenaga penjualan inhouse dan website serta saluran tidak langsung melalui sales associated, joint partner, dan sosial media.

Customer Relationships, Hubungan pelanggan yang dibangun oleh ROE saat ini lebih banyak melalui interaksi langsung dan media sosial. Untuk pelanggan potensial dan pelanggan spesial untuk tujuan upselling maupun retensi biasanya ROE mengeluarkan biaya entertaint juga menggunakan media sosial dengan ucapan selamat ulang tahun ataupun memberikan tag terhadap foto atau kegiatan yang melibatkan pelanggan untuk membuat pelanggan gembira.

Revenue streams merupakan aliran pendapatan atau pemasukan yang diterima oleh perusahaan. Untuk saat ini $95 \%$ omzet dari ROE didapat dari konser ROE dan $5 \%$ sisanya masih dari terapi individual pelanggan. 


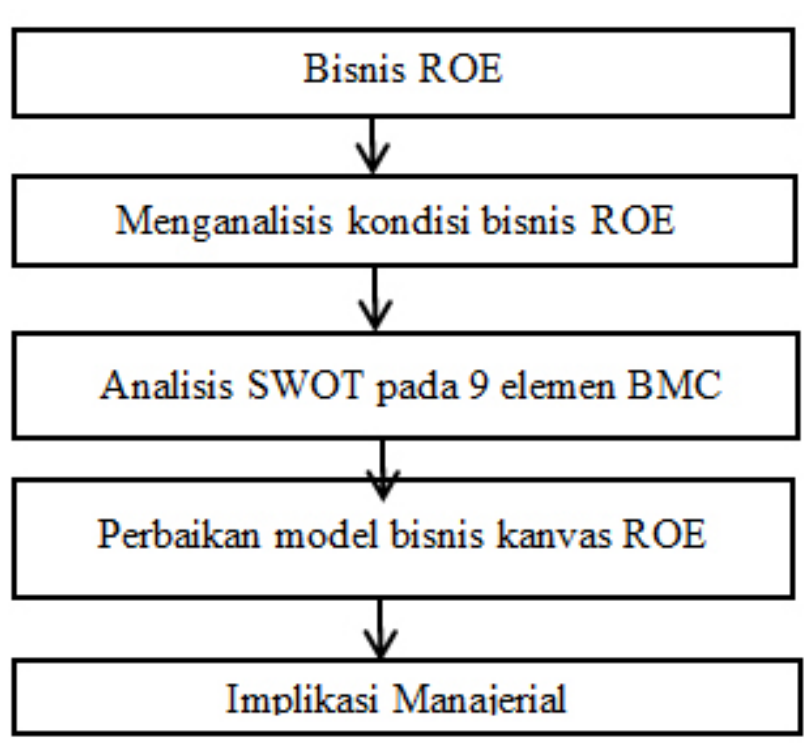

Gambar 1. Kerangka pemikiran penelitian

Key resources dapat dibedakan menjadi dua jenis, yaitu tangible berupa kantor, SDM, dan alat pendukung operasional, sedangkan intangible yaitu berupa ilmu metode ROE itu sendiri, pengetahuan berkaitan dengan musik lainnya, substansi materi yang akan dibawakan, manajemen panggung, serta manajemen perusahaan lainnya.

Key activities menggambarkan hal-hal terpenting yang dilakukan perusahaan agar model bisnisnya dapat berjalan dengan baik. Key activities di ROE dimulai dari proses penjualan, pra produksi, pelaksanaan konser dan manajemen pasca konser.

Key Partnerships menggambarkan jaringan pemasok dan pelanggan dan mitra bisnis lainnya. ROE memiliki mitra kunci antara lain Band Pengiring, penari dan vocal group, perusahaan sound dan lighting serta beberapa alat musik, penyedia souvenir.

Cost Structure, dari bisnis ROE terbagi menjadi dua komponen biaya, yaitu variable cost dan fixed cost.

Hasil pemetaan dari setiap elemen model bisnis dituangkan dalam satu lembar kanvas, sebagai potret model bisnis ROE untuk saat ini bisa dilihat pada Gambar 2.

\section{Analisis SWOT ROE Berdasar BMC}

Setelah mengidentifikasi elemen BMC di ROE saat ini maka tahap selanjutnya adalah melakukan analisis SWOT pada setiap elemen BMC saat ini. Analisis
SWOT pada masing-masing elemen BMC pada ROE dapat dilihat pada Tabel 3. Menurut Pearce dan Robinson (2008), analisis SWOT didasarkan pada asumsi bahwa strategi yang efektif diciptakan dari adanya keselarasan antara yang baik dari faktor internal perusahaan dan situsai eksternal yang memengaruhi perusahaan. Untuk itu dapat dirumuskanya strategi-strategi untuk perbaikan model bisnis ROE, yaitu sebagai berikut :

\section{S-O Strategi}

a. Dengan beragam segmen yang bisa tergarap dan juga luasnya pasar perusahaan dapat menawarkan joint partner dan franchise di berbagai tempat dengan pengawasan manajemen melalui penciptaan sistem yang baku baik operasional maupun konser ROE sendiri.

b. ROEdapatmelakukaninovasiberupapengembangan produk dan layanan yang sudah ada saat ini agar lebih memiliki daya jual yang tinggi dan mampu menjangkau segmen dan wilayah secara luas.

c. Kerjasama dengan mitra utama tidak hanya sebatas untuk talent tapi juga kerjasama dalam akses permodalan dan juga pemasaran yang selama ini belum dilakukan oleh ROE. Mengaktifkan program CSR bersama mitra untuk dipakai ROE menjalankan program ROE Sahabat, yaitu konser ROE secara gratis berkeliling ke segmen tertentu..

d. Secara rutin dan terjadwal mengadakan publik seminar untuk membantu penjualan dan peningkatan brand awareness ROE, hal ini belum pernah dilakukan sama sekali oleh ROE, padahal beberapa produk motivasi dan motivator-motivator terkenal cukup efektif membesarkan bisnisnya dengan melakukan seminar publik yang rutin.

\section{W-O Strategi}

a. Kurangnya SDM dalam hal operasional dan manajemen perusahaan maka perlu diadakannya penambahan karyawan, setelah itu akan dilakukan pelatihan sesuai dengan fungsinya untuk meningkatkan kualitas pelayanan dan kemampuan dalam menjalankan setiap fungsi. Sehingga ketergantungan terhadap owner dapat diminamalisir.

b. Perlunya mengembangkan produk turunan yang mampu menjangkau segmen lain baik berupa jasa atau barang untuk memperluas pasar dan juga memperbesar revenue stream misal menciptakan ROE Konser berdasar konten materi seperti ROE for 
Leader dan ROE for Sales Champion dan sejenisnya. Selain itu juga berupa barang merchandise seperti kaos musik motivasi, mug, album ROE dan musik terapi yang dapat diakses melalui aplikasi khusus.

c. Selama ini ROE tidak dapat fokus untuk berkembang dikarenakan masih seringnya permintaan paket dari pelanggan (plus EO) yang menguras banyak sumber daya dari ROE dan rentan untuk adanya komplain diluar ROE, untuk itu perlu dibuat hal yang baru meliputi struktur organisasi, pembiayaan maupun operasionalnya secara terpisah antara tim EO dan ROE.

d. Belum optimalnya pemasaran dari ROE dikarenakan belum adanya program khusus yang dibuat menarik untuk mendukung kinerja penjualan maupun menaikan brand awareness dari ROE, perlunya optimalisasi kanal-kanal pemasaran melalui teknologi informasi terutama sosial media disamping memperkuat sales inhouse ataupun non inhouse.

e. Jakarta masih menjadi pusat potensial market pagi ROE, untuk itu diperlukannya pembukaan kantor di Jakarta agar pemasaran lebih efektif dan efisien.

\section{S-T Strategi}

a. Pengembangan produk dengan memperhatikan trend atau disesuaikan dengan permintaan pasar terutama mampu mengkomunikasikan pentingnya dampak pelatihan ROE ke pelanggan untuk menciptakan repeat order yang selama ini jarang dilakukan untuk pelanggan yang sudah pernah menghadiri konser ROE, misal dengan mengembangkan berdasar level lanjutan, yaitu ROE intermediate atau ROE Advance.

b. Menciptakan standarisasi pemilihan dan evaluasi mitra utama serta memperkuat aspek legal dalam kontrak-kontrak dengan mitra utama.

c. Memanfaatkan pendekatan hubungan perusahaan dengan karyawan dan ex. Karyawan secara baik dan profesional dan membangun kepemimpinan perusahaan yang menciptakan suasana kerja nyaman dan mendukung loyalitas karyawan.

4. W-T Strategi

a. Bekerja sama dengan mitra eksternal untuk merapikan perpajakan dan administrasi keuangan agar accountable agar mudah mendapatkan akses pembiayaan.

\begin{tabular}{|c|c|c|c|c|c|}
\hline \multirow[t]{2}{*}{$\begin{array}{l}\quad \text { Key Partners } \\
\text { - Band Jatim, } \\
\text { Jabodetabek,Jateng } \\
\text { dan Sumatera } \\
\text { - Arranger } \\
\text { - Sound dan Lighting } \\
\text { rental } \\
\text { - Perajin Souvenir }\end{array}$} & $\begin{array}{l}\quad \text { Key Activities } \\
\\
\text { - Proses penjualan } \\
\text { - Pra konser } \\
\text { - Manajemen produksi } \\
\text { - Konser } \\
\text { - Manajemen pasca } \\
\text { Konser }\end{array}$ & \multirow{2}{*}{\multicolumn{2}{|c|}{$\begin{array}{l}\text { Value Propositions } \\
\text { - Metode unik } \\
\text { dan pertama di } \\
\text { Indonesia } \\
\text { - Customise } \\
\text { - Pengalaman baru } \\
\text { - High Impact }\end{array}$}} & \begin{tabular}{l}
\multicolumn{1}{c}{$\begin{array}{c}\text { Customer } \\
\text { Relationships }\end{array}$} \\
- Komunikasi SMS, \\
telepon, email, \\
website, media \\
sosial, \\
- Kunjungan
\end{tabular} & \multirow{2}{*}{$\begin{array}{l}\text { Customer } \\
\text { Segments } \\
\text { - ROE Star } \\
\text { (Karyawan) } \\
\text { - ROE for Student } \\
\text { - ROE for Kids } \\
\text { - ROE Sahabat }\end{array}$} \\
\hline & $\begin{array}{l}\quad \text { Key Resources } \\
\text { - Tangible (kantor, } \\
\text { SDM, alat pendukung } \\
\text { operasional) } \\
\text { - Intangible (HAKI ROE } \\
\text { dan ilmu SDM) }\end{array}$ & & & $\begin{array}{l}\text { Channels } \\
\\
\text { - Langsung (sales } \\
\text { inhouse dan } \\
\text { website) } \\
\text { - Tidak langsung } \\
\text { (sales associated, } \\
\text { sosial media) }\end{array}$ & \\
\hline \multicolumn{3}{|c|}{$\begin{array}{l}\text { Variabe Cost: } \\
\text { Biaya trainer, talent dan crew, biaya peralatan dan } \\
\text { perlengkapan, biaya akomodasi, transport dan konsumsi dan } \\
\text { dokumentasi. } \\
\text { Fixed Cost: } \\
\text { Biaya gaji, tunjangan karyawan, biaya pemasaran, biaya } \\
\text { inventaris kantor. }\end{array}$} & \multicolumn{2}{|c|}{$\begin{array}{l}\text { - Konser ROE } \\
\text { - Terapi musik individual }\end{array}$} & \\
\hline
\end{tabular}




\begin{tabular}{|c|c|c|c|c|}
\hline Aspek & Kekuatan & Kelemahan & Peluang & Ancaman \\
\hline $\begin{array}{l}\text { Customer } \\
\text { Segments }\end{array}$ & $\begin{array}{l}\text { Luasan cakupan } \\
\text { segmen dan luasan } \\
\text { wilayah segmentasi }\end{array}$ & $\begin{array}{l}\text { Sumber daya yang ada belum } \\
\text { siap untuk menggarap semua } \\
\text { segmen dan wilayah pasar } \\
\text { yang luas, belum adanya } \\
\text { standar penjualan dan } \\
\text { pelayanan tiap segmen, dan } \\
\text { belum adanya konser publik }\end{array}$ & $\begin{array}{l}\text { Segmen lain yang belum } \\
\text { tergarap, Undirect } \\
\text { Customer seperti EO } \\
\text { serta kelas publik }\end{array}$ & $\begin{array}{l}\text { Nama besar lain di } \\
\text { pelatihan soft skills }\end{array}$ \\
\hline $\begin{array}{l}\text { Value } \\
\text { Propositions }\end{array}$ & $\begin{array}{l}\text { Produk yang unik, } \\
\text { materi dan harga } \\
\text { bisa di custom, dan } \\
\text { pelayanan yang baik } \\
\text { pada saat konser ROE. }\end{array}$ & $\begin{array}{l}\text { inkonsistensi mitra utama, } \\
\text { belum adanya produk turunan } \\
\text { dan adanya sistem paket }\end{array}$ & $\begin{array}{l}\text { Membuat versi konser } \\
\text { lain dan produk } \\
\text { tambahan dan membuat } \\
\text { divisi khusus EO yang } \\
\text { terpisah }\end{array}$ & $\begin{array}{l}\text { Potensi adanya plagiat } \\
\text { produk }\end{array}$ \\
\hline Channels & $\begin{array}{l}\text { Adanya sales inhouse } \\
\text { dan non inhouse } \\
\text { lain serta mulai } \\
\text { menggunakan IT } \\
\text { untuk pemasaran }\end{array}$ & $\begin{array}{l}\text { Sales inhouse dan non } \\
\text { inhouse belum optimal, } \\
\text { Program IT belum optimal, } \\
\text { banyak wilayah belum } \\
\text { tergarap }\end{array}$ & $\begin{array}{l}\text { Perkuatan kolaborasi } \\
\text { inhouse dan non } \\
\text { inhouse dan peluang } \\
\text { sistem franchise serta } \\
\text { optimalisasi IT untuk } \\
\text { promosi perusahaan }\end{array}$ & $\begin{array}{l}\text { Saluran mudah ditiru } \\
\text { dan kemungkinan } \\
\text { sales inhouse dan non } \\
\text { inhouse bekerjasama } \\
\text { dengan pesaing }\end{array}$ \\
\hline $\begin{array}{l}\text { Customer } \\
\text { Relationship }\end{array}$ & Turun langsung owner & $\begin{array}{l}\text { Belum tersedianya sistem dan } \\
\text { anggaran cukup untuk service } \\
\text { excellent }\end{array}$ & $\begin{array}{l}\text { Ketersediaan sistem } \\
\text { dan anggaran pelayanan } \\
\text { dan word of mouth } \\
\text { pelanggan serta } \\
\text { optimalkan IT }\end{array}$ & $\begin{array}{l}\text { Bervariasinya karakter } \\
\text { dan perilaku dari } \\
\text { pelanggan }\end{array}$ \\
\hline $\begin{array}{l}\text { Revenue } \\
\text { Streams }\end{array}$ & $\begin{array}{l}\text { Sumber pendapatan } \\
\text { utama ROE Konser }\end{array}$ & $\begin{array}{l}\text { Masih dari satu sumber dan } \\
\text { by project atau tidak rutin }\end{array}$ & $\begin{array}{l}\text { Penambahan sumber } \\
\text { pendapatan lain dan } \\
\text { penciptaan mitra bisnis } \\
\text { diluar ROE }\end{array}$ & $\begin{array}{l}\text { Pemotongan } \\
\text { anggaran instansi } \\
\text { dan perusahaan } \\
\text { serta sistem dan } \\
\text { pembayaran LS atau } \\
\text { setelah acara }\end{array}$ \\
\hline $\begin{array}{l}\text { Key } \\
\text { Resources }\end{array}$ & $\begin{array}{l}\text { Produk unik sudah } \\
\text { ada HAKI dan sumber } \\
\text { daya untuk talent } \\
\text { ROE profesional } \\
\text { serta fasilitas kantor } \\
\text { memadai }\end{array}$ & $\begin{array}{l}\text { Tenaga pengelola operasional } \\
\text { dan manajemen yang kurang } \\
\text { dan kantor masih berpusat di } \\
\text { Bogor serta IT belum optimal }\end{array}$ & $\begin{array}{l}\text { Pengembangan IT dan } \\
\text { pembukaan kantor di } \\
\text { Jakarta }\end{array}$ & $\begin{array}{l}\text { SDM yang rentan } \\
\text { dibajak dan stok SDM } \\
\text { untuk operasional } \\
\text { yang sedikit }\end{array}$ \\
\hline $\begin{array}{l}\text { Key } \\
\text { Activities }\end{array}$ & $\begin{array}{l}\text { Adanya sistem baku } \\
\text { dalam penyampaian } \\
\text { materi ROE dan } \\
\text { ada beberapa SOP } \\
\text { kegiatan operasional }\end{array}$ & $\begin{array}{l}\text { Implementasi SOP belum } \\
\text { optimal, peran owner masih } \\
\text { dominan dan kantor jauh dari } \\
\text { pusat pelanggan }\end{array}$ & $\begin{array}{l}\text { Kerjasama dengan } \\
\text { pihak lain untuk } \\
\text { pengembangan produk } \\
\text { dan operasional agar } \\
\text { lebih efisien dan efektif }\end{array}$ & $\begin{array}{l}\text { pergantian karyawan } \\
\text { terutama tim } \\
\text { penjualan }\end{array}$ \\
\hline $\begin{array}{l}\text { Key } \\
\text { Partnership }\end{array}$ & $\begin{array}{l}\text { Sebaran talent } \\
\text { ROE di berbagai } \\
\text { wilayah, hubungan } \\
\text { kekeluargaan dengan } \\
\text { mitra dan tersedia } \\
\text { alternatif mitra kunci }\end{array}$ & $\begin{array}{l}\text { Pertemua masih mendekati } \\
\text { waktu konser, belum adanya } \\
\text { standar pemilihan vendor } \\
\text { dan tidak semua kerjasama } \\
\text { dengan legal kontrak }\end{array}$ & $\begin{array}{l}\text { Memperluas jaringan } \\
\text { usaha lainnya terutama } \\
\text { pemasaran dan } \\
\text { keuangan }\end{array}$ & $\begin{array}{l}\text { Adanya wan prestasi } \\
\text { dari mitra kunci dan } \\
\text { kenaikan harga dari } \\
\text { mitra kunci }\end{array}$ \\
\hline $\begin{array}{l}\text { Cost } \\
\text { Structure }\end{array}$ & $\begin{array}{l}\text { Biaya pokok } \\
\text { penjualan terprediksi } \\
\text { dengan baik di RAB } \\
\text { khusus ROE }\end{array}$ & $\begin{array}{l}\text { Cash flow terganggu karena } \\
\text { sistem paket EO, kecilnya } \\
\text { biaya pemasaran,alokasi biaya } \\
\text { karyawan besar pelaporan } \\
\text { perpajakan dan keuangan } \\
\text { buruk }\end{array}$ & $\begin{array}{l}\text { Kerjasama dengan } \\
\text { pihak perbankan dan } \\
\text { kerjasama dengan pihak } \\
\text { IT untuk efisiensi biaya } \\
\text { marketing }\end{array}$ & $\begin{array}{l}\text { Ketatnya pelaporan } \\
\text { perpajakan dan } \\
\text { kenaikan harga dari } \\
\text { mitra kunci }\end{array}$ \\
\hline
\end{tabular}


b. Melakukan pelatihan dan seminar untuk menerapkan sistem-sistem perusahaan yang baik, mulai dari sistem administratif, sistem franchise, hingga sistem yang berhubungan dengan kesejahteraan karyawan. Saat ini yang menjadi fokus perusahaan yaitu turn over karyawan yang tinggi terutama di tim penjualan.

c. Kesejahteraan karyawan perlu ditingkatkan oleh perusahaan dengan mendaftarkan karyawan untuk ikut serta dalam program BPJS dan memberikan insentive bonus tambahan agar karyawan merasa betah dan nyaman bekerja untuk perusahaan.
Pengembangan suatu model bisnis agar sempurna dan serta bagaimana cara untuk mengimplementasikan secara efektif dan efisien membutuhkan kehatihatian serta harus mempertimbangkan pengaruh dari internal maupun eksternal perusahaan (Mannsfield dan Fourie, 2003) atas pertimbangan itu rumusan strategi dirumuskan melalui analisis SWOT yang dapat dituangkan pada sebuah tabel strategi (Tabel 4).

\section{Perbaikan Model Bisnis Kanvas ROE}

Berikut penjelasan dari masing-masing elemen blok bangunan pada model bisnis kanvas ROE yang telah mengalami perbaikan yaitu sebagai berikut :

Tabel 4. Rumusan Strategi SWOT ROE

\begin{tabular}{|c|c|c|}
\hline & $\begin{array}{l}\quad \text { Strengths }(\mathrm{S}) \\
\text { 1. Produk mencakup seluruh segmen } \\
\text { di masyarakat } \\
\text { 2. Luasnya wilayah pemasaran ROE } \\
\text { 3. Produk yang unik dan custom } \\
\text { sudah HAKI } \\
\text { 4. Mitra kunci yang efektif dan } \\
\text { professional } \\
\text { 5. Menjangkau konsumen secara } \\
\text { langsung dan tidak langsung }\end{array}$ & $\begin{array}{l}\quad \text { Weaknesses }(\mathrm{W}) \\
\text { 1. Masih tergarap satu segmen saja } \\
\text { 2. Belum adanya produk turunan } \\
\text { 3. Belum bisa berdiri sebagai produk } \\
\text { mandiri karena disertainya dengan } \\
\text { banyaknya sistem paket dengan EO } \\
\text { 4. Pemasaran yang masih belum optimal } \\
\text { 5. Lemahnya manajemen operasional dan } \\
\text { fungsi owner yang sangat dominan } \\
\text { 6. Kantor di Bogor sehingga kurang } \\
\text { efektif dan efisien }\end{array}$ \\
\hline $\begin{array}{l}\quad \text { Opportunities }(\mathrm{O}) \\
\text { 1. Bisnis dapat dikembangkan } \\
\text { dengan sistem joint partner atau } \\
\text { franchise } \\
\text { 2. Banyaknya segmen belum } \\
\text { tergarap } \\
\text { 3. Tidak memiliki batasan inovasi } \\
\text { 4. Pemanfaatan mitra keuangan, } \\
\text { tax dan perbankan } \\
\text { 5. Program promosi berdasar } \\
\text { segmen konsumen }\end{array}$ & $\begin{array}{l}\text { S-O Strategy } \\
\text { 1. Penawaran joint partner atau } \\
\text { franchise di kota-kota potensial. } \\
\text { 2. Inovasi produk yang sudah ada } \\
\text { agar lebih menarik dan memiliki } \\
\text { nilai jual tinggi. } \\
\text { 3. Membuka akses permodalan dan } \\
\text { kerjasama dengan pihak lain untuk } \\
\text { memperkuat operasional dan } \\
\text { manajemen perusahaan terutama } \\
\text { bidang pemasaran. } \\
\text { 4. Secara rutin mengadakan publik } \\
\text { seminar untuk peningkatan brand } \\
\text { awareness. }\end{array}$ & $\begin{array}{l}\text { W-O Strategy } \\
\text { 1. Penambahan dan pelatihan karyawan } \\
\text { dan mitra bisnis yang sesuai dengan } \\
\text { fungsi dan strategi perusahaan. } \\
\text { 2. Mengembangkan produk turunan baik } \\
\text { berupa jasa dan barang. } \\
\text { 3. Secara tegas memisahkan antara ROE } \\
\text { konser dan sistem paket EO baik } \\
\text { sistem, pembiayaan, struktur organisasi } \\
\text { maupun operasionalnya. } \\
\text { 4. Membuat program promosi menarik } \\
\text { calon pelanggan dengan baik melalui } \\
\text { direct selling maupun pemanfaatan IT. } \\
\text { 5. Membuka kantor di Jakarta. }\end{array}$ \\
\hline $\begin{array}{l}\text { Threats }(\mathrm{T}) \\
\text { 1. Kemungkinan munculnya } \\
\text { pesaing dan persaingan dengan } \\
\text { produk substitusi } \\
\text { 2. Adanya mitra bisnis yang wan } \\
\text { prestasi } \\
\text { 3. Sulitnya mendapatkan akses } \\
\text { pembiayaan dan ketatnya sistem } \\
\text { pelaporan perpajakan } \\
\text { 4. Pembajakan karyawan yang } \\
\text { bekerjasama dengan pesaing. }\end{array}$ & $\begin{array}{l}\text { S-T Strategy } \\
\text { 1. Mengembangkan produk dan } \\
\text { layanan yang sudah ada dengan } \\
\text { lebih menarik dan kompetitif serta } \\
\text { cepat penyebarannya } \\
\text { 2. Menyusun sistem pemilihan, } \\
\text { evaluasi dan pelatihan untuk mitra } \\
\text { utama dan memperkuat aspek legal } \\
\text { 3. Memanfaatkan pendekatan } \\
\text { hubungan perusahaan dengan } \\
\text { karyawan secara baik untuk } \\
\text { menciptakan kenyamanan }\end{array}$ & $\begin{array}{l}\text { W-T Strategy } \\
\text { 1. Bekerja sama dengan mitra eksternal } \\
\text { untuk merapikan perpajakan dan } \\
\text { administrasi keuangan agar bankable } \\
\text { dan accountable agar mudah } \\
\text { mendapatkan akses pembiayaan. } \\
\text { 2. Melakukan pelatihan untuk } \\
\text { menerapkan sistem-sistem perusahaan } \\
\text { yang baik. }\end{array}$ \\
\hline
\end{tabular}




\section{Customer Segment}

ROE akan mengoptimalkan segmen yang sudah ada yang disebut sebagai direct customer dan membidik segmen potensial baru, yaitu undirect customer $(\mathrm{EO} \&$ franchise), public, dan retail customer.

\section{Value Propositions}

Dengan adanya penambahan segmen maka perlunya penciptaan produk baru untuk menambah nilai perusahaan berdasar materi yang lebih bervariasi baik untuk in house training maupun public training. Selain itu ROE juga akan menjual produk retail berupa ROE Album, merchandise, buku, dan aplikasi.

\section{Channels}

Dalam menjangkau pelanggan, ROE menggunakan saluran langsung dan saluran tidak langsung. saluran langsung dengan menambah jumlah tenaga penjualan dan membuka kantor representatif di Jakarta. Sedangkan saluran tidak langsung dilakukan dengan mengoptimalkan website, media sosial, dan melalui aktivasi SEO pada Google, booster follower untuk sosmed, memperbanyak marketing associated dan bekerja sama dengan pihak lain untuk joint partner atau franchise

\section{Customer Relationship}

Manajemen ROE akan menyusun panduan budaya kerja di perusahaan dan SOP khusus service excellent, mengoptimalkan IT dalam pelayanan, menerbitkan kartu alumni ROE dan juga meningkatkan anggaran entertainment.

\section{Revenue Stream}

Untuk memperkuat dan memperbesar revenue stream ROE mengambil langkah yaitu dengan memperbanyak varian materi untuk inhouse training dan melakukan publik seminar secara rutin, selain itu juga menciptakan produk merchandise seperti kaos musik motivasi dan mug dijual secara langsung di konser ROE dan juga dapat diakses melalui internet, serta sistem franchise untuk metode ROE di beberapa kota besar tertentu diharapkan mampu menambah revenue stream ROE.

\section{Key Resources}

Dalam menjalankan bisnisnya ROE berpusat di Bogor kurang efektif dan efisien terutama untuk penetrasi ke pasar Jakarta yang masih menjadi pusat pelanggan untuk itu ROE untuk itu ROE akan membuka kantor di Jakarta.

\section{Key Activities}

Untuk aktivitas kunci ROE akan mengoptimalkan kinerjanya dengan merekrut karyawan yang terafiliasi dibagian marketing yang bertugas mencari database calon pelanggan dengan berbagai cara, melakukan outsourcing untuk aktivitas pra konser dan manajemen aktivitas kunci di produk retail.

\section{Key partnership}

Dalam pengelolan mitra kunci ini perlu dioptimalkan, yaitu dengan membuat standar layanan pendukung acara (talent) untuk menjaga kinerja yang optimal pada pelaksanaan konser, membuat standarisasi untuk perekrutan mitra kunci baru dalam proses pengadaan kebutuhan talent, crew, perlengkapan dan peralatan dan semuanya dibuat dalam kontrak, memperluas jaringan bisnis dalam bidang marketing dengan para mitra promosi, merekrut mitra untuk pembuatan produk retail, konsultan keuangan dan juga perbankan.

\section{Cost Structure}

Bisnis yang baik harus mampu menjaga kontinuitas usaha, faktor-faktor yang dapat menjaga kontinuitas usaha antara lain, yaitu likuiditas, solvabilitas, soliditas, rentabilitas, maupun credit waardigheid (Alma, 2010). Sistem paket (EO)baik pengerjaan maupun pembiayaan akan dilakukan dengan merekrut EO partner sehingga ROE tidak mengeluarkan biaya untuk sistem paket yang selama ini cashflow dan keuntungan dari ROE banyak tergerus oleh sistem paket tambahan (EO), karena bagaimanapun juga bisnis adalah suatu kegiatan menyediakan barang dan jasa dengan maksud mendapatkan laba (Griiffin dan Ebert, 2007), hal ini dilakukan untuk mempertahankan laba. Alokasi biaya untuk pemasaran juga ditambah sekaligus dipilih metode pemasaran yang efisien dan efektif. Juga terdapat penambahan biaya untuk peningkatan kualitas SDM serta mengalokasikan biaya bekerjasama dengan mitra konsultan di bidang finansial dan tax. Perbaikanperbaikan pada model bisnis kanvas oleh ROE dapat dilihat pada Gambar 3 . 


\begin{tabular}{|c|c|c|c|c|c|}
\hline \multirow[t]{2}{*}{$\begin{array}{l}\quad \text { Key Partners } \\
\text { - Band Indonesia } \\
\text { Timur, Band } \\
\text { Jabodetabek, Band } \\
\text { Jateng \& Yogya, } \\
\text { Sumatera } \\
\text { - Mind Therapy Arr. } \\
\text { - Sound dan Lighting } \\
\text { - Perajin Souvenir } \\
\text { - Tarian } \\
\text { - *mitra pemasaran } \\
\text { (SEO, booster } \\
\text { sosmed) } \\
\text { - *mitra penyedia } \\
\text { produk retail } \\
\text { - * mitra konsultan } \\
\text { keuangan, pajak dan } \\
\text { perbankan }\end{array}$} & $\begin{array}{l}\text { Key Activities } \\
\text { - Proses Penjualan } \\
\text { - Pra Konser } \\
\text { - Manajemen Produksi } \\
\text { - Konser ROE } \\
\text { - Manajemen Pasca } \\
\text { Konser } \\
\text { - *standar perekrutan dan } \\
\text { pelayanan mitra utama } \\
\text { - *subkontrak } \\
\text { manajemen pra konser } \\
\text { dan sistem EO } \\
\text { - *Manajemen produksi } \\
\text { retail }\end{array}$ & \multirow{2}{*}{\multicolumn{2}{|c|}{$\begin{array}{l}\text { Value Propositions } \\
\text { - Pelatihan soft } \\
\text { skills dengan } \\
\text { Metode unik } \\
\text { dan pertama di } \\
\text { Indonesia } \\
\text { - Customise } \\
\text { - Pengalaman baru } \\
\text { - High Impact } \\
\text { - * produk turunan } \\
\text { yang lebih } \\
\text { variatif berdasar } \\
\text { segmen dan } \\
\text { materi } \\
\text { - *produk retail } \\
\text { dengan berbagai } \\
\text { bentuk dan jenis }\end{array}$}} & $\begin{array}{l}\text { Customer } \\
\text { Relationships }\end{array}$ & $\begin{array}{l}\text { Customer } \\
\text { Segments } \\
\text { - ROE Star } \\
\text { (Karyawan) } \\
\text { - ROE for Student } \\
\text { (SMU dan } \\
\text { - Mahasiswa) } \\
\text { - ROE for Kids } \\
\text { (SD \& SMP) } \\
\text { - ROE Sahabat } \\
\text { (Panti Sosial dan } \\
\text { - Pesantren) } \\
\text { - *Undirect } \\
\text { Customer } \\
\text { - *Public } \\
\text { Customer } \\
\text { - * Retail Customer }\end{array}$ \\
\hline & $\begin{array}{l}\text { Key Resources } \\
\text { - Tangible (kantor, } \\
\text { alat musik, mobil } \\
\text { operasional, SDM, alat } \\
\text { pendukung operasional) } \\
\text { - Intangible (HAKI ROE } \\
\text { dan ilmu SDM) } \\
\text { - *Restukturisasi } \\
\text { organisasi ROE } \\
\text { - *Penyediaan mobil } \\
\text { penjualan } \\
\text { - *Perekrutan lead } \\
\text { contributor } \\
\text { - *Penambahan } \\
\text { tenaga penjualan dan } \\
\text { pemasaran }\end{array}$ & & & $\begin{array}{l}\text { Channels } \\
\text { - Langsung (tenaga } \\
\text { penjual inhouse dan } \\
\text { website) } \\
\text { - Tidak langsung } \\
\text { (tenaga penjual } \\
\text { associated, sosial } \\
\text { media, sales } \\
\text { partnership, spooter) } \\
\text { - *SEO dan Booster } \\
\text { Sosmed } \\
\text { - * Kantor Jakarta } \\
\text { - * Franchise atau joint } \\
\text { partner }\end{array}$ & \\
\hline \multicolumn{3}{|c|}{$\begin{array}{l}\text { Variabe Cost: } \\
\text { Biaya trainer, talent dan crew, biaya peralatan dan perlengkapan, } \\
\text { biaya akomodasi, transport dan konsumsi dan dokumentasi } \\
\text { Fixed Cost: } \\
\text { Biaya Gaji, tunjangan karyawan, biaya pemasaran, biaya } \\
\text { inventaris kantor, *Biaya pelatihan SDM dan *Biaya konsultan } \\
\text { financial dan tax }\end{array}$} & \multicolumn{3}{|c|}{$\begin{array}{l}\text { - Konser ROE } \\
\text { - Terapi individual } \\
\text { - *Varian konser ROE } \\
\text { - *Produk retail (merchandise, apps, album) } \\
\text { - *Pendapatan dari franchise dan joint partner }\end{array}$} \\
\hline
\end{tabular}

Gambar 3. Model bisnis kanvas ROE yang telah diperbarui (Tanda bintang $\left({ }^{*}\right)$ merupakan strategi tambahan)

\section{Implikasi Manajerial}

Dari hasil perbaikan model bisnis ROE maka secara otomatis menciptakan implikasi manajerial yang juga diperlukan pengambilan keputusan strategis secara cepat. Karakteristik manajemen strategis yang membedakan adalah penekanan pada pengambilan keputusan strategis (Wheelen et al. 2012). Menurut Nenonen dan Storbacka (2010) menyatakan bahwa membangun model bisnis dapat menjelaskan keputusan strategis besar yang dibuat oleh perusahaan. Untuk itu Langkah-langkah sebagai keputusan strategis Implikasi Manajerial ROE, yaitu ROE perlu meningkatkan fokus kinerja terutama untuk channels dari ROE yang belum optimal terbukti dengan belum tercapainya target kinerja yang diinginkan. Pemanfaatan teknologi sebagai saluran utama menjadi hal yang penting seperti website interaktif, CRM dan pembuatan konten promo pada 
sosmed serta memperbanyak tenaga penjualan yang lebih profesional dan segera membuka kantor dijakarta. Perlunya perekrutan mitra kunci(EO), untuk menangani sistem paket yang sering menggangu cashflow sehingga anggaran dapat dialokasikan untuk biaya pemasaran dan pengembangan produk lain. Pengembangan varian baru untuk menangkap segmen yang belum tergarap dapat segera disusun silabus materi maupun material promosi sehingga secara cepat dapat terkomunikasikan ke pelanggan potensial. Selanjutnya, ROE perlu mensosialisasikan rencana perusahaan kepada pihak internal perusahaan. Hal ini terkait apa saja yang perlu disiapkan, anggaran biaya dan persiapan teknis lainnya yang akan dibuatkan rencana aksi dan dievaluasi setiap minggu oleh manajemen untuk memastikan tingkat eksekusi.

\section{KESIMPULAN DAN SARAN}

\section{Kesimpulan}

Hasil penelitian diketahui bahwa pemetaan kondisi bisnis pada saat ini terdapat beberapa elemen yang sudah baik dan perlu dipertahankan tetapi juga ada yang perlu diperbaiki terutama pada channels yang belum optimal sehingga berdampak pada kecilnya revenue stream, selain itu perlunya untuk memperbaiki aktivitas kunci terutama menjaga cash flow dan profit yang berpengaruh pada cost structure dari ROE.

Analisis SWOT pada ROE maka didapatkan strategi yang terdiri dari SO strategi yang fokus pada inovasi produk dan pengembangan mitra bisnis, sedangkan strategi WO diprioritaskan dengan pengelolaan aktivitas kunci agar lebih efisien dan efektif dengan merekrut mitra event organizer dan optimalisasi IT untuk pemasaran serta pembukaan kantor Jakarta. Untuk ST fokus pada penyebaran produk inovasi baru dan menciptakan budaya kerja yang membuat loyal karyawan dan juga perlakuan mitra secara profesional. Untuk strategi WT diprioritaskan pada perbaikan struktur dan laporan keuangan perusahaan dengan merekrut mitra baru dan juga optimalisasi kinerja SDM dengan pelatihan .

Adanya perbaikan pada model bisnis kanvas baru ROE terutama dengan perbaikan channels dengan penambahan tenaga penjualan serta pemanfaatan IT untuk promosi, selain itu di aktivitas kunci perlu diefisienkan karena berpengaruh terhadap struktur biaya dan revenue stream perusahaan. Value proposition ditambahkan dengan produk varian baru untuk menangkap potensi baru, yaitu undirect customer, public customer, dan juga retail customer.

\section{Saran}

Bisnis ROE harus fokus pada perbaikan-perbaikan BMC baru dan menjabarkan dalam rencana aksi secara detail, konsisten melaksanakan dan mengevaluasi serta perbaikan secara terus menerus pada rencana aksi atau program yang telah dilakukan. Bagi peneliti lain untuk memperkaya dan mempertajam penelitian sejenis disarankan dapat menggunakan alat analisis lain seperti AHP atau blue ocean strategy.

\section{DAFTAR PUSTAKA}

Agustiadi A, Syarief R, Nurrochmat D. 2018. Strategi pengembangan bisnis rental Mobil Wiralodra 27 dengan pendekatan model bisnis kanvas. Jurnal Aplikasi Bisnis dan Manajemen 4(1):138-150. http://dx.doi.org/10.17358/jabm.4.1.138.

Ahdiyana M. 2010. Dimensi organizational citizenship behaviour (OCB) dalam kinerja organisasi organinasi. Jurnal Efisiensi 10(1): 1-10.

Alma B. 2010. Kewirausahaan untuk Mahasiswa dan Umum. Ed ke-1. Bandung: Indonesia.

Amanullah, Azhar ANA, Faizah N. 2015. Comparison of Business Model Canvas (BMC) among the three consulting companies. International Journal of Computer Science and Information Technology Research 2(1): 29-41.

Amreny FF. 2012. Analisis tingkat kepuasan pelanggan terhadap mutu layanan antar (delivery service) di restoran kfc cabang ahmad yani Makassar. Jurnal Ekonomi Universitas Hasanudin 5(10): $67-70$.

Aspara J, Lamberg JA, Laukia A, Tikkanen H. 2011. Strategic management of business model transformation: lessons from Nokia. Management Decision 49(4): 622-647. https:// doi.org/10.1108/00251741111126521.

Azis A, Kadir R, Alam S. 2013. Strategi Pengembangan pelabuhan dari sistem konvensional ke full terminal operator peti kemas PT. pelindo IV (persero) cabang tarakan. Jurnal Ekonomi Universitas Hasanudin 6(1): 32-44.

Boedianto LP, Harjanti D. 2015. Strategi pengembangan bisnis pada kedai selaris dengan pendekatan 
business model canvas. Jurnal Agora 3(2): 292 301.

Bonazzi FLZ, Zilber MA. 2014. Innovation and business model: a case study about integration of innovation funnel and business model canvas. Journal Review of Business Management 16(53): 616-637. https://doi.org/10.7819/rbgn. v16i53.1812.

Cavalcante, Kesting, Ulhoi, 2011. Business model dynamics and innovation: (re)establishing the missing linkages. Journal Management Decision 49(8):1327-1342. https://doi. org/10.1108/00251741111163142.

Dewa A, Lukman M, Setiadi D. 2016. Pariwisata kreatif dan kegiatan ekstrakurikuler berbasis bambu dalam pengembangan model bisnis CV Suratin Bamboo. Jurnal Manajemen dan Agribisnis. 13(3): $227-239$.

Eppler MJ, Hoffman F, Bresciani S. 2011. New business models through collabborative idea generation. International journal of Innovation Management 15(6): 1323-1341. https://doi. org/10.1142/S1363919611003751.

Griffin RW, Ebert RJ. 2007. Bisnis. Ed ke-8. Jakarta: Erlangga

Hone T, De Lin, Hey Su. 2011. A Grounded theory on the business model structure of Google. International Journal of electronic Business Management 9(3): 231-242.

Leschke J. 2013. Business model mapping: A new tool to encourage entrepreneurial activity and accelerate new venture creation. Journal of Marketing Development and Competitiveness 1(4): 28-32.
Maghfirah. 2012.E-Business analysis of Garut University (UNIGA) using the Business Model Canvas. International Journal of Science and Research 2(1): 1-5.

Mansfield GM, Fourie LCH. 2004. Strategy and business models - strange bedfellow?. a case for convergence and its evolution into strategic architecture. South Africa Journal of Business Management 35: 35-44.

Nenonen S, Storbacka K. 2010. Business model design: conceptualizing networked value cocreation. International Journal of Quality and Service Sciences 2(1):43-59. https://doi. org/10.1108/17566691011026595

Osterwalder A, Pigneur Y. 2012. The Business Model Generation. Jakarta: PT. Elex Media Komputindo.

Pearce J, Robinson R. 2008. Manajemen Strategis: Formulasi, Implementasi dan Pengendalian. Jakarta: Salemba Empat.

Solihin AI. 1995. Investasi Modal Manusia Melalui Pendidikan: Pentingnya Peran Pemerintah. Jakarta: Mini Economica 23.

Shafer SM, Smith HJ, Linder JC. 2005. The power of business models. Journal of Business Horizons 48(3): 199-207. https://doi.org/10.1016/j. bushor.2004.10.014.

Thamrin I. 2016. Strategi pengembangan bisnis kemitraan minuman teh siap saji yourtea dengan pendekatan model bisnis kanvas [tesis]. Bogor: Institut Pertanian Bogor.

Wheelan TL. 2008. Manajemen Strategis. Yogyakarta: Andi Publisher.

Zott C, Amit R, Massa L. 2011.The business model: recent developments and future research. Journal of Management 2(3): 12-22. 